\title{
Effect of educational program using immediate feedback to improve the performance level of steeplechase for female students of the Faculty of Physical Education - Monofia University.
}

\section{Azza Mohamed El-Emary}

Assistant Professor, Faculty of Physical Education, Sadat City University, Egypt.

\section{Introduction}

$\mathrm{T}$ he world is witnessing now a huge revolution in information technology and the broad scientific progress so that it became a competition between the countries based on the capabilities and scientific and technological capabilities through the rapid development of technology in general and educational technology in particular.

Educational technology has become a necessity for all students in all stages of education to raise the level of efficiency and effectiveness of educational process, as the technology is not a purpose itself but is a tool to reach faster to the real purpose of education development which is development of thought, persuasion, understanding and link it with Scientific application and figuring scientific personality through educational technology(1)

The educational method is a basic element of the practical education process which is indispensable if we want a good education to students and can be defined as a set of educational materials and devices and educational attitudes and educational activities necessary to increase the effectiveness of educational communication that occur inside the classroom and outside (2)
Learning includes all the knowledge acquired by the individual meanings and ideas, trends and tendencies and emotions, habits and capabilities motor skills and mobility, whether this acquisition done by intended deliberate manner or unintended casual manner.( 3 )

feedback has a huge importance in the field of Physical Education as the practice of various sports activities able to achieve internal organization of the sensory nerves and motor nerves, and different muscles, as a result of feedback, this organization helps adjust respond more and more. (4)

The physical education in general and athletics particular is a fertile field for many of the studies and research that aim to benefit from the application of scientific theories in the fields of various knowledge _ and the concept of feedback should be used in a manner contribute to improve the performance and time of performance jumped steeplechase for students of Faculty of Physical Education Menoufia University.

Through the work of researcher at the faculty and the International Federation of Athletics this competition research topic was chosen because it is the first research to the knowledge of the researcher to start that competition at the faculties of Physical Education for Girls and try to identify the 
effect feedback on improvement of time of performance and degree of performance for the student to jump steeplechase.

The importance of research that this competition has never been studied in faculties of physical education for girls, especially as they are included in the international program for athletics.

\section{Objectives:}

The research aims to design an educational program for nutrition and to identify: -

1. The effect of the proposed program on the level of performance of female students for the steeplechase competition.

2. The effect of the proposed program on time of performance of steeplechase contest.

\section{Hypothesis :}

1. There are significant differences between the pre and post measurement for the post measurement in the time of performance variables and degree of performance in steeplechase competition for students.

Procedures of the study:

Methodology:
The researcher used the experimental method where it is most appropriate to the nature of this study.

\section{The research community:}

The research community have been identified from students of the Faculty of Physical Education Menofia University, Egypt.

\section{Sample search:}

The research sample included 40 female students from the fourth division as one experimental group.

\section{The proposed educational program:}

- The application of the proposed educational program to jump steeplechase have Been scheduled within the academic content scheduled for the fourth band in order to illustrate the importance of the achievement of its objectives.

- The location of the application of the program and tools used in faculty.

- Educational program was implemented in the second semester of the academic year $2012-2013$.

\section{Pre measurement:}

The researcher conducted pre measurement of the search at 10-2-2013

Table 1

Descriptive of Time and Score $n=40$

\begin{tabular}{|c|c|c|c|}
\hline Variables & Mean & SD \pm & Skewness \\
\hline Time & 209.950 & 11.697 & $0.137-$ \\
\hline performance & 1.0750 & 0.266 & 2.354 \\
\hline
\end{tabular}

The results of the table is an indication to Mean and standard deviation and Skewness coefficient of research variables in the pre measurement. 
The duration of the program:

- Design tutorial contents to 90 minutes are the parts of the lecture where the education is about steeplechase jump .

- Tutorial included a three-week training modules.

- The program consists of 11 modules.

\section{Post measurement:}

The researcher conducted post measurement of the search at 3-3-2013

\section{Statistical treatment:}

The researcher used in statistical data processing statistical program SPSS by using the following treatments:

- Mean.

- Standard deviation.

- Skewness coefficient.

- Test "T" to calculate the significance differences between the averages.

Graphic formats.

The percentages of change

Results :

Table 2

Defiance between per and Post measurement

\begin{tabular}{|c|c|c|c|c|c|c|}
\hline \multicolumn{2}{|c|}{ Variables } & Mean & SD & Dif, of Mean & " T "value & $\triangle$ \\
\hline \multirow{2}{*}{ Time } & Pre & 209.950 & 11.698 & \multirow{2}{*}{35.275} & \multirow{2}{*}{$* 66.272$} & \multirow{2}{*}{$\% 20.195$} \\
\hline & Post & 174.675 & 11.207 & & & \\
\hline \multirow{2}{*}{ performance } & Pre & 1.075 & 0.267 & \multirow{2}{*}{0.875} & \multirow{2}{*}{$* 7.000$} & \multirow{2}{*}{$\% 81.395$} \\
\hline & Post & 1.950 & 0.714 & & & \\
\hline
\end{tabular}

" $T$ "value $0.05 \geq 1.96$

Figure 1

The percentage of rate for between per and Post measurement 


\section{Discussion:}

The results described in table (1), (2) showed the existence of statistically significant differences between the measurement pre and post measurement in the variables of research and this indicates that the tutorial topic by the researcher to the research sample, which showed its effects on variables research for the benefit of post measurement

This confirms the above that the variable experimental impact in improving the time and degree of performance to jump steeplechase for students of Faculty of Physical Education Menoufia University, and in line with what referred to by Derfatescy Drovatzky (1975) in the in and out feedback information help beginners to discover the errors of their performance in the determination of how to fix it through guidance for this performance, which depends on the contact between the Directive and the sensory inputs to produce outputs appropriate to motor response members and thus directing the learning process to achieve good performance. (5)

The results also described in table (2) and form (1) showed an improvement in the sample at the time of performance and degree of performance _ the researcher believes that this is due to the direct advantage of feedback information of the educational program referred to by Stalling quoting Smith that the learner in need for both types of feedback together _ and indicates that there is a certain point where the learner stands in need to get this information either after the completion of performance or after the performance of one of the attempts, particularly motor skills complex or fast performance in which learner can not knows his mistakes and as a result of this performance only by sensory reaction feeding. (6)

And discovering performance mistakes must be done by the player seeing his mistakes by using modern methods and this is consistent with what was referred to by Adams (1978) that the modern means are responded to actively, such as closed-circuit television registrar Visible _ and where it is used television as a mirror seeing them as learner himself to correct performance and to develop This performance (7).

This confirms that it is necessary to have the availability factor feedback within educational situations faced by the teacher in the environment of education, where it guides beginner learner when they make mistakes or, it's also guides them to movements, which need to be strengthened or modified, so it is one of the most important factors that regulate learning and perfecting the performance of motor skills. (8)

Consistent with that "Rink" in which he brought that feedback is divided based on the time frame, in which the feedback is immediate and is given during or after the performance directly, or feedback postponed given after the performance after a period of time, and must not be a delayed feedback degree make the individual forget his performance of the skill and therefore can not link the Performing mistakes and guidance by the teacher.

\section{Conclusions:}

1. The percentage of the improved level of performance for research sample for time is $20.195 \%$ and for performance score $81.395 \%$ and this 
shows the impact of the proposed training program on feedback.

2. The knowledge of performance mistakes by both types of feedback lead to effective learning and thus to improve the level of performance.

3. The training program to teach jumping steeplechase competition can be considered a quick way to develop the technical stages of the trainees and competition, which affects the level of performance improvement and performance score.

\section{Recommendations:}

As a result of what illustrated by the results of this study the researcher recommends the following:

1. The use of in and out feedback by the player seeing his performance, photographic and life model with students of faculty of Physical Education upgrade their skill level.

2. Provide the resources necessary to use this method in the faculties of Physical Education.

3. Use the same method when teaching the beginners so that they can acquire the technical stages of the competitions in a positive way because performance technical mistakes can not be repaired easily if beginner accustomed to perform wrongly, _ this is a result of transmission of the impact of education in a negative light.

\section{References}

1. Mohamed Saad Zaghloul (2001 m): IT education and methods of Physical Education, the center of the book for publication, Cairo.P.P.[78]
2. Nawal Ibrahim Shaltout, Mervat on Khafajah (2007): Teaching Methods in Physical Education (Teaching of teaching and learning), the second part, the first edition, meet Printing House, Printing and Publishing, Alexandria.P.P.[91]

3. Ahmed Ezzat Rageh 1979: Psychology assets Egyptian Knowledge House -
Cairo.P.P.[201]

4. Shares Syed Abdullah 1980: feedbacks and their impact on basketball skills _ Master is Nchorh _ Faculty of Physical Education for Girls, Helwan _ University of Cairo.P.P[2]

5. Drowatzky , J . N. 1975 : Motor learning prinviples and prectice burgess pub;ishing company . P.P. $[83$

6. Staling s, ; M. 1982 : Motor learning from theory to practice, the C. V. mosby com . P.P.[85]

7. Adams, J. A. 1978 : Theoretical issue for knowledge of results, I. N. G. E stelmach ( ED ), information processing in motor control and learning, New Youk . P.P.[195]

8. Ragaa Mahmoud Abu Allam (1993 m): Educational Psychology, Tabahavh, Darkulm, Kuwait.P.P.[363]

9. Rink E. J. ( 1998) :Teaching physical concepts and application, 5th ed, Mccrow Hill Companies, Boston . P.P.[35]

10. Abeer Ahmad Rashad Hassan 2000: The effect of feed on the education of backe skill shot put with mentally handicapped Master is Nmchorh _ Faculty of Physical Education for Girls, Helwan _ University of Cairo.

11. Abdul Aziz Abdul Majid Mohamed 1985: backe feed and its impact on learning the triple jump _ Physical Education College of Lenin, Helwan _ University of Cairo.

12. Hossam Radwan full Mohamed 1994: The effect of using some liquid feed backe on a flat improve the performance of emerging races barriers _ Unpublished Master Thesis, Faculty of Physical Education for Lenin, Helwan _ University of Cairo.

13. Jambor A. \& Weekes, Esther, M. 1995 :Video tape feed back make it mor effective, Journal of physical education v66, nt, feb . 
